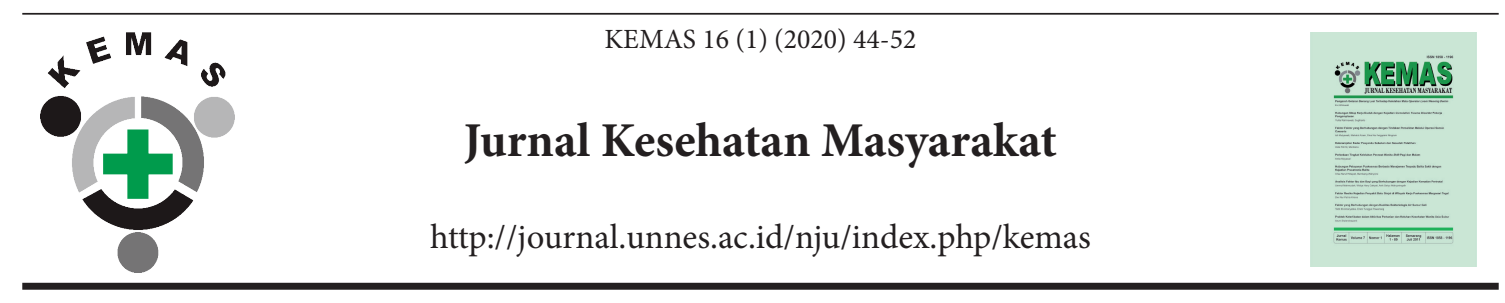

\title{
Is the Frequency of Smoking Affecting the Risk of Abusing Cannabis?
}

\author{
Nurul Huriah Astuti ${ }^{1 凶}$, Sutanto Priyo Hastono² \\ ${ }^{1}$ Faculty of Health Science, University of Muhammadiyah Prof. DR. HAMKA, Indonesia \\ ${ }^{2}$ Faculty of Public Health, University of Indonesia, Indonesia
}

\section{Article Info \\ Article History: \\ Submitted February 2019 \\ Accepted February 2020 \\ Published July 2020 \\ Keywords: \\ Teens smokers, cannabis \\ abuse, survival analysis \\ DOI \\ https://doi.org/10.15294/ \\ kemas.v16i1.18063}

\begin{abstract}
The results of previous study found that teens that had a smoking habit were 14 times more likely to smoke cannabis than those who did not smoke. This study aims to determine the relationship between the frequency of smoking and cannabis abuse done through survival analysis. The research samples were 708 students of cannabis abusers who were previously preceded by smoking. The results of this study found that durability or length of time for abusing cannabis was mostly $1-4$ years. The Wilcoxon test results concluded that there was a difference in survival to abusing cannabis among the frequency groups of smoking. Multivariate analysis also showed that the more number of cigarettes consumed, the greater the risk for abusing cannabis after being controlled by confounders. Conclusion of this study, the frequency of smoking affects the survival rate and the amount of risk to abusing cannabis.
\end{abstract}

\section{Introduction}

Survey data of the Basic Health Research was found that the proportion of people who smoke every day and occasionally in Indonesia in 2013 was $29.3 \%$ of the total population ( Indonesian Ministry of Health, 2018). This number declined slightly in 2018, which was $28.8 \%$ of the population. However, if the proportion was calculated based on the total population of Indonesia in 2013 which was equal to 250 million people, then there were around 73.25 million Indonesian people who smoke every day and every so often in 2013. That number actually increased to 76.32 million since the population of Indonesia also enlarged to 265 million. Meanwhile, a survey of students in 18 provinces in Indonesia showed that one out of three or four students had ever smoked (National Narcotics Agency of the Republic of Indonesia \& Center for Health Research, University of Indonesia, 2017).

Smoking habits are known to be the main cause of lung disease, like chronic obstructive pulmonary disease (Diaz-Guzman \& Mannino, 2014). Smoking is said to cause respiratory problems and acute changes in the lung organs, including changes in respiratory flow resistance and pulmonary irritation. In early adulthood, smoking can affect respiratory function. Proper nutritional intake is preventive therapy which is known to prevent inflammation, obstruction, and lung function deficits. But unfortunately, research showed there were differences in nutritional intake between active smokers and nonsmokers (Gates et al., 2014; Indraswari et al., 2018). Smoking habits not only cause negative effects on active smokers but also second hand smoke or those who smoke released by smokers (Öberg, et al., 2011). A study showed a positive relationship between the length of time of other people's smoke exposure per day with urine cotinine levels and also there was a significant relationship between other people's smoke 
exposure by co-workers with urine cotinine levels (Nurjanah \& Mufid, 2014).

Smoking habits, based on the results of previous studies, would increase the risk of drug abuse especially cannabis (Astuti, 2016; Badiani et al., 2015; Hindocha et al., 2015; Mayet, Aurelie, 2011). Based on the theory, it is known that there are three theories related to the relationship of smoking with cannabis abuse. First theory is "the Gateway Theory" (GT) which states that the development of consumption of addictive substances follows an advanced process of the habit of consuming prohibited substances, such as cigarettes and/ or alcohol. After consuming cigarettes/alcohol, it is predicted that it will continue to illicit substance abuse with types of soft drugs, such as cannabis, and then followed by consuming prohibited types of hard drugs, such as cocaine or heroin (Secades-Villa et al., 2015; Prince van Leeuwen et al., 2011). Second, the theory of the Common Liability to Addiction (CLA) which states that substance consumption both licit and illicit is influenced by genetics and individual vulnerability, such as individual vulnerability to deviations and dependency in family conditions. Unlike the GT theory, CLA theory states that (a) the "choice" of what substances is consumed is first influenced by the factors mentioned above, namely genetics and individual vulnerability; and (b) There is no order in the process of developing substance abuse (Korhonen et al., 2008; Prince van Leeuwen et al., 2011). Third, the theory of "Route of Administration Model" (ROM) which states that the techniques of addictive substances used (for example inhalation or smoked) will affect the type of addictive substances that will be consumed later. This theory provides an explanation for why are smokers at risk of abusing cannabis? Because both smoking and abusing cannabis have the same way in terms of how to consume, this is smoked or inhaled (Prince van Leeuwen et al., 2011).

Survey data in Indonesia showed that cannabis was the most often drug type misused by all students in Indonesia ( National Narcotics Agency of the Republic of Indonesia \& Center for Health Research, University of Indonesia, 2017). Cannabis was also the most widely used of drug and the last year used of drug by Indonesian students surveyed by the National Narcotics Agency (BNN) and the University of Indonesia Health Research Center (PPKUI) in 2016 ( National Narcotics Agency of the Republic of Indonesia \& Center for Health Research, University of Indonesia, 2017). Another study using a sample of teenagers living in the French metropolitan city explained the relationship between cigarette smoking habits and cannabis abuse. The results showed that the majority of cannabis abusers were preceded by cigarette smoking, only $2 \%$ of adolescent cigarette smokers and cannabis abusers that formerly started by using cannabis (Mayet et al., 2011).

Related to the frequency of smoking, research conducted on residents of Australian twins and siblings aged $12-46$ years showed that the smoking habits which is routine was associated with an early opportunity to abuse cannabis and their first time to misuse it. Each Hazard Ratio/HR (the risk of a group to experience hazard or failure or event if they were exposed rather than not exposed) was 2.35 (95\% CI $2.16-2.56$ ) and 3.49 (95\% CI. 3.18 - 3.83) (Agrawal et al., 2013).

In this study, researchers analyzed the data from the National Survey on the Development of Drug Abuse and Narcotics Illicit Circulation in Student Groups in Indonesia in 2011 conducted by the National Narcotics Agency (BNN) and the Health Research Center of Indonesia University (PPKUI). There were also three purposes of this study. First, knowing the time of endurance or the length of time (in years) to survive from the first time cigarette smoking until the very first time abuse cannabis. Second, knowing the rate of survival to cannabis abuse based on the frequency of cigarette smoking. Third, knowing the relationship between the frequency of cigarette smoking to the survival of cannabis abuse after being controlled by a variable history of drinking alcohol, families exposed to alcohol and/or drugs, separate from parents at least for six months, and peer influence.

\section{Method}

The study design used in this study followed the study design conducted on the data used, namely the National Survey on the Development of Illicit Drug Abuse and 


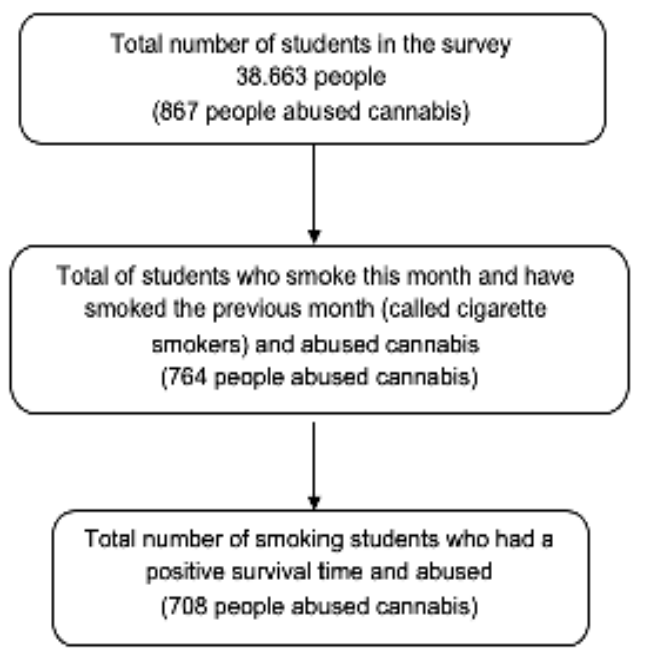

Figure 1. Research Sample Restriction

Circulation in Student Groups in Indonesia in 2011 conducted by the National Narcotics Agency (BNN) and the Health Research Center of Indonesia University (PPKUI). The cross sectional study design was also used in the survey.

The study populations in this research were middle school, high school and college students who became respondents in the National Survey on the Development of Illicit Drug Abuse and Circulation in student groups in 2011 which were around 38,663 people. The samples of this study were students who smoked in the last month/in this month and students who had smoked in previous months, and assumed smoking habits preceded or coincided with misused of cannabis Hence, after being selected only for smokers (smokers this month and smokers in the previous month) and it had a positive survival time (smoking habit preceded or coincided with cannabis abuse), then total sample prepared for the analysis was 708 people (Figure 1).

Based on the large sample formula according to Machin (1997) for survival analysis, then $\mathrm{HR}=3.49$ and $\mathrm{n} 1$ (the proportion of cannabis abusers in routine cigarette smokers) was $55 \%$ and $\mathrm{n} 2$ (the proportion of cannabis as abusers on non-routine smokers) was $46 \%$ (Agrawal et al., 2013). Then the Power of the test in 708 samples analyzed was more than $99 \%$.

Furthermore, to facilitate the interpretation of the analysis results, the researchers did the following related data. First, the value of survival time 0 to less than 0.5 (0 $<$ survival time value $<0.5$ ) was recoded to 0.5 (there were 103 respondents with a value of 0 and 332 respondents with a value between 0.0082 to 0.4328$)$. Second, the researchers made changes to the frequency group of smoking from secondary data used. Initially the frequency of smoking was divided into 7 groups, namely rarely smoking, $<5$ cigarettes/ week, $\geq 5-7$ cigarettes/week, $>7$ - 35 cigarettes/ week, >35 - 70 cigarettes/week, >70 - 140 cigarettes/week, and >140 cigarettes/week, then the researcher recoded it into four groups, namely rarely smoking, <5-7 cigarettes/week, $>7$ - 35 cigarettes/week, and $>35$ cigarettes/ week. The cut-off determination of the four groups was based on the closeness of the line on the Kaplan Meier curve. The rare definition of smoking referred in this study is those who did not smoke on the month when the interview was conducted.

\section{Results and Discussion}

The results of this study indicated that the majority of cigarette smokers who abused cannabis were male (93.4\%); the age range of the youngest cigarette smoker was 7 years $(2.8 \%)$ and the oldest was 21 years $(0.1 \%)$; the majority started cigarette smoking at the age of $10-14$ years $(60 \%)$. The mean/average age of starting smoking was 13.15 years and the median was 13 years. The average age or 
middle age of the first time cigarette smoking obtained in this study was almost the same as the results of the study on a sample of teenagers living in French metropolitan city that showed the average age at first smoking was 13.4 years (Mayet et al., 2011).

Regarding the early age of abusing cannabis, the youngest one was 8 years $(0.3 \%)$ and the oldest one was 25 years (0.4\%). However, the majority began to abuse cannabis at the age of $15-19$ years (65.6\%). The mean age of starting cigarette smoking is 16.19 and the median age of starting to abuse cannabis is 16 years. The average age of misusing cannabis in this study slightly differed from other studies which got an average age of misusing cannabis was 15.1 years or ranging from 15 years (Mayet et al., 2011)

The researchers then carried out a further analysis of the correlation between the first time age of cigarettes smoking and the first time age of abusing cannabis. Through correlation analysis and linear regression, the value of $r=0.551$ and the value of $\rho$ value $<0.0001$ was obtained. Thus, it could be concluded that the correlation between the first time age of cigarettes smoking and the first time age of abusing cannabis showed a strong and positive pattern of relationships. These conclusions corroborate predictions obtained from previous studies stating that the age at first cigarette smoking will increase the risk of misusing cannabis (Prince van Leeuwen et al., 2011). Other research also found that cigarette smoking before the age of 13 years is an important and strong predictor of abusing cannabis (Korhonen et al., 2008).

In addition, the results of Kaplan Meier's analysis found that the length of time for abusing cannabis in student smoking who misused cannabis was a minimum of 0.5 years (14.5\%) and a maximum of 13 years $(0.3 \%)$, while the most was 1 - 4 year (61.5\%). Whereas the mean time interval was 3.10 years $(95 \% \mathrm{CI}$ : 2.9 - 3.3) and the median (50\% sample) was 2.0 years (95\% CI: 1.8 - 2.2).

Table 1. Frequency Distribution of Smoker Students that Misused cannabis in Indonesia in 2011

\begin{tabular}{|c|c|c|c|}
\hline Variable & & $\begin{array}{l}\text { Total } \\
\mathrm{N}=708\end{array}$ & $\begin{array}{l}\text { Percentage } \\
(\%)\end{array}$ \\
\hline \multirow[t]{4}{*}{ Age of starting smoking } & $<10$ years & 55 & 8 \\
\hline & $10-14$ years & 428 & 60 \\
\hline & $15-19$ years & 219 & 31 \\
\hline & $20-24$ & 6 & 1 \\
\hline \multirow[t]{5}{*}{ Age of using cannabis } & $5-9$ years & 2 & 0.3 \\
\hline & $10-14$ years & 153 & 21.6 \\
\hline & $15-19$ years & 464 & 65.6 \\
\hline & $20-24$ years & 86 & 12.1 \\
\hline & $25-29$ years & 3 & 0.4 \\
\hline \multirow[t]{4}{*}{ Smoking frequency } & Rarely smoking & 64 & 9.0 \\
\hline & $<5-7$ cigarettes/week & 132 & 18.6 \\
\hline & $>7-35$ cigarettes/week & 205 & 29.0 \\
\hline & >35 cigarettes/week & 307 & 43.4 \\
\hline \multirow{4}{*}{$\begin{array}{l}\text { Length of time/survival time from } \\
\text { smoking to misusing cannabis }\end{array}$} & $1-4$ years & 435 & 61.5 \\
\hline & $5-9$ years & 159 & 22.5 \\
\hline & $10-14$ years & 11 & 1.5 \\
\hline & $15-19$ years & 103 & 14.6 \\
\hline
\end{tabular}

Source :Cconducted by the National Narcotics Agency (BNN) and the Health Research Center of Indonesia University (PPKUI), 2011 
Table 2. Mean and Median Time Intervals from the First Start of Smoking to Misusing Cannabis of Student Smoking that Abused Cannabis in Indonesia in 2011

\begin{tabular}{llll}
\hline Number of Sample $(\mathrm{n})$ & & Mean & Median \\
\hline \multirow{2}{*}{708} & Value & 3.1 & 2.0 \\
& $95 \%$ CI & $2.9-3.3$ & $1.8-2.2$ \\
\hline
\end{tabular}

Table 3. Mean and Median Length of Time from First Time Smoking to Misusing Cannabis Based on the Smoking Frequency of Smoking Student that Abused Cannabis in Indonesia in 2011

\begin{tabular}{lllll}
\hline \multirow{2}{*}{ Cigarette Smoking Frequency } & \multicolumn{3}{l}{ Mean } & \multicolumn{3}{l}{ Median } \\
\cline { 2 - 5 } & Value (years) & $95 \% \mathrm{CI}$ & $\begin{array}{l}\text { Value } \\
\text { (years) }\end{array}$ & $95 \% \mathrm{CI}$ \\
\hline Rarely smoking & 3.5 & $2,732-4,331$ & 2 & $1.4-2.5$ \\
$<5-7$ cigarettes/week & 2.6 & $2,243-3,045$ & 2 & $1.6-2.4$ \\
$>7-35$ cigarettes/week & 3.7 & $2,427-3,017$ & 2 & $1.7-2.3$ \\
$>35$ cigarettes/week & 3.5 & $3,206-3,729$ & 3 & $2.7-3.3$ \\
$\begin{array}{l}\text { Relatively } \\
\begin{array}{l}\text { Log Rank Test } \\
\text { (Mantel-Cox) }\end{array}\end{array}$ & 3.1 & $3,926-3,282$ & 2 & $1.8-2.2$ \\
\hline
\end{tabular}

The results of this study were in line with other studies which showed that cigarette smoking will open up opportunities for abusing cannabis in a relatively short time and have a strong relationship with cannabis drug abuse (Guxens et al, 2007 in (Mayet et al., 2011). Moreover, cigarette smoking habits also has the potential to cause cannabis abuse, where cigarette smoking precedes cannabis abuse (Weinberger et al., 2018; Hindocha et al., 2015). The results of this study also reinforced the awareness of the behavior of cannabis abuse in cigarette smokers. That is, when people start cigarette smoking then it will not be up to five years, they will probably start consuming other types of addictive substances such as cannabis regardless of how fast the process starts from cigarette smoking to abusing cannabis. The outcomes of this study were also in line with the theory of Route of Administration which predicts that the type of addictive substance used today will affect other types of addictive substances consumed in the future. In more detail, it is explained that those who cigarette smoke will have the opportunity to abuse cannabis because the way to consume these two substances is similar, namely by inhalation (Van Leeuwen et al., 2011). Besides, the results of this study were indeed in accordance with "The Gateway Theory" (GT) which states that consuming cigarettes and cannabis is a sequential process. This means that consuming cigarettes or alcohol will potentially be followed by other substance abuse in the hard drug use group, such cannabis (Mayet et al., 2011).

Meanwhile, if it was analyzed based on the frequency group of smoking, the median length of time from first cigarette smoking to abusing cannabis indicated that those who rarely cigarette smoke till cigarette smoke with a frequency of 35 cigarettes/week have a 2-year abuse period, while students who smoke with a frequency of $>35$ cigarettes/week have longer time to abuse Cannabis, i.e. 3 years (table 3 ). The Log Rank Test results showed a value of $\rho$ value $<0,0001$ which means that a difference in the length of survival time to abusing cannabis is based on the frequency of cigarette smoking. Though, it is not known exactly why those who smoke more than 35 cigarettes a day have a longer survival time to abuse cannabis.

The results of life table analysis showed 
Table 4. Life Table of Cannabis Abuse Based on Smoking Frequency of Student Smokers in 2011

\begin{tabular}{|c|c|c|c|c|c|}
\hline Smoking Frequency & $\begin{array}{l}\text { Time } \\
\text { Interval }\end{array}$ & $\begin{array}{l}\text { Number of "Safe" } \\
\text { Subjects at the } \\
\text { beginning of the } \\
\text { interval }\end{array}$ & $\begin{array}{l}\text { Number of } \\
\text { Sensors during } \\
\text { Interval }\end{array}$ & $\begin{array}{l}\text { Number of Events } \\
\text { During Interval }\end{array}$ & $\begin{array}{l}\text { Cumulative } \\
\text { Probability } \\
\text { at the End }\end{array}$ \\
\hline \multirow[t]{7}{*}{ Rarely smoking } & 0 & 4,085 & 3,108 & 43 & 0.98 \\
\hline & 5 & 934 & 807 & 17 & 0.95 \\
\hline & 10 & 110 & 98 & 4 & 0.89 \\
\hline & 15 & 8 & 5 & 0 & 0.89 \\
\hline & 20 & 3 & 2 & 0 & 0.89 \\
\hline & 25 & 1 & 1 & 0 & 0.89 \\
\hline & 0 & 3,149 & 2,552 & 107 & 0.94 \\
\hline \multirow[t]{4}{*}{$<5-7$ cigarettes/week } & 5 & 490 & 419 & 24 & 0.86 \\
\hline & 10 & 47 & 39 & 1 & 0.83 \\
\hline & 15 & 7 & 5 & 0 & 0.83 \\
\hline & 20 & 2 & 2 & 0 & 0.83 \\
\hline \multirow[t]{5}{*}{$>7$ - 35 cigarettes/week } & 0 & 1,746 & 1,199 & 171 & 0.85 \\
\hline & 5 & 376 & 291 & 33 & 0.73 \\
\hline & 10 & 52 & 45 & 1 & 0.70 \\
\hline & 15 & 6 & 3 & 0 & 0.70 \\
\hline & 20 & 3 & 3 & 0 & 0.70 \\
\hline \multirow[t]{6}{*}{$>35$ cigarettes/week } & 0 & 1,399 & 640 & 217 & 0.80 \\
\hline & 5 & 542 & 383 & 85 & 0.61 \\
\hline & 10 & 74 & 54 & 5 & 0.54 \\
\hline & 15 & 15 & 12 & 0 & 0.54 \\
\hline & 20 & 3 & 1 & 0 & 0.54 \\
\hline & 25 & 2 & 2 & 0 & 0.54 \\
\hline
\end{tabular}

Source :Cconducted by the National Narcotics Agency (BNN) and the Health Research Center of Indonesia University (PPKUI), 2011

that at intervals of 0 - 4 years, the survival rate of cigarette smoking groups seen as a cumulative probability of survival (End) was 0.98 . This meant that at intervals of $0-4$ years, as many as $98 \%$ of students who rarely cigarette smoke still have not misused cannabis or at intervals of $0-4$ years there were $2 \%$ of students who rarely cigarette smoke though abuse cannabis. The survival rate to abusing cannabis at these intervals was increasing based on the increasing number of cigarettes consumed. Students with a frequency of smoking $<5-7$ cigarettes/ week was 0.94 , the group with the frequency of smoking $>7-35$ cigarettes/week was 0.85 , and the group with a frequency $>35$ cigarettes/week was 0.80 . Likewise, the next time interval has the same pattern, namely the more the number of cigarettes consumed, the more survival rate for abusing cannabis increased (Table 4).
Unfortunately, the researchers did not get the results of other studies that revealed the value of the survival rate of cannabis abuse based on the frequency of cigarette smoking so that researchers could not compare the results of this study with other studies. However, according to the researchers, the results of this study corroborate previous research which stated that those who cigarette smoke regularly (100 or more cigarettes in life - based on the standards of the CDC USA, 2007) are at higher risk for getting an opportunity to abuse cannabis and more early to abuse cannabis (Agrawal et al., 2013). This condition is increasingly driven by the discovery that those who routinely smoke feel the pleasure faster when they first abuse cannabis than those who do not routinely cigarette smoke (those who have never cigarette smoked or have ever cigarette smoked but 
Table 5. Final Model of the Correlation between the Frequency of Smoking and Status of Cannabis Abuse of Students Smoker in Indonesia 2011

\begin{tabular}{|c|c|c|c|c|c|}
\hline Variable & $\mathrm{B}$ & SE & Pvalue & $\mathrm{HR}$ & $95 \% \mathrm{CI}$ \\
\hline \multicolumn{6}{|l|}{ Cigarette Smoking Frequency } \\
\hline Rarely smoking & & & & 1 & \\
\hline$<5-7$ cigarettes/week & 0.910 & 0.154 & $<0.0001$ & 2.5 & $1.8-3.3$ \\
\hline$>7$ - 35 cigarettes/week & 1.378 & 0.147 & $<0.0001$ & 4.0 & $3.0-5.3$ \\
\hline$>35$ cigarettes/week & 1.521 & 0.143 & $<0.0001$ & 4.6 & $3.5-6.0$ \\
\hline \multicolumn{6}{|l|}{ History of Drinking Alcohol } \\
\hline No & & & & 1 & \\
\hline Yes & 1.341 & 0.117 & $<0.0001$ & 3.8 & $3.0-4.8$ \\
\hline \multicolumn{6}{|l|}{ Family Exposed to Alcohol and/or Narcotics } \\
\hline No exposure & & & & 1 & \\
\hline Middle exposure & -0.230 & 0.088 & 0.009 & 0.8 & $0.7-1.0$ \\
\hline Bad exposure & 0.326 & 0.343 & 0.343 & 1.4 & $0.7-2.7$ \\
\hline \multicolumn{6}{|l|}{ Separated from parents at least for six months } \\
\hline No & & & & 1 & \\
\hline Yes & 0.234 & 0.124 & 0.059 & 1.3 & $1.0-1.6$ \\
\hline \multicolumn{6}{|l|}{ Peer influence } \\
\hline No influence & & & & 1 & \\
\hline Good influence & 1.675 & 0.094 & $<0.0001$ & 5.3 & $4.4-6.4$ \\
\hline Bad influence & 1.882 & 0.124 & $<0.0001$ & 6.6 & $5.1-8.4$ \\
\hline Separated from parents at least for six months ${ }^{\star} \mathrm{T}-\mathrm{Cov}$ & -0.081 & 0.031 & 0.010 & 0.9 & $0.9-1.0$ \\
\hline
\end{tabular}

never more than 100 cigarettes in their lifetime) (Agrawal et al., 2013).

The final model of multivariate analysis showed that the history of drinking alcohol, families exposed to alcohol and/or drugs, separated from parents at least six months, and peer influence were confounding variables on the relationship between the frequency of cigarette smoking and cannabis abuse in 2011 in Indonesia (Table 5).

This final model also showed the pattern that the higher the frequency of cigarette smoking or the more number of cigarettes consumed by student smokers in Indonesia in 2011, the faster the hazard/risk value for abusing cannabis compared to student smokers in Indonesia who rarely cigarette smoking in 2011 (table 5). Overall, the final model explains:

Hazard ratio/risk for the occurrence of cannabis abuse of student smokers in Indonesia in 2011 who smoke with a frequency $<5-7$ cigarettes/week was 2.5 times faster than students in Indonesia who rarely smoke in 2011 after being controlled by variable of drinking alcohol, family exposed to alcohol and/or drugs, separate from parents at least for six months, and peer influence (95\% CI: 1,8 - 3,3).

Hazard ratio/risk for the occurrence of cannabis abuse in student cigarette smokers who smoke with a frequency $>7-35$ cigarettes/ week was 4.0 times faster than students in Indonesia in 2011 who rarely cigarette smoke after being controlled by a history of drinking alcohol, family exposed to alcohol and/or drugs, separate from parents at least for six months, and peer influence (95\% CI: 3.0 - 5.3).

Hazard ratio for the occurrence of cannabis abuse in student cigarette smokers who smoke with a frequency of $>35$ cigarettes/ week was 4.6 times faster than students in Indonesia in 2011 who rarely cigarette smoke after being controlled by a variable drinking alcohol history, family exposed to alcohol and or drugs, separate from parents at least for six months, and peer influence 95\% CI: 3.5 - 6.0).

The first confounder found in this study was a history of drinking alcohol. The history of drinking alcohol was indeed found in several 
studies as a risk factor for abusing cannabis. Research conducted in Dutch adolescents, for example, showed that teens who drank alcohol at an early age would increase their risk of abusing cannabis with a hazard ratio of 1.43 and 95\% CI: 1.21 .7 (Prince van Leeuwen et al., 2011). Other previous studies also revealed that alcohol and cannabis could occur simultaneously (Brière et al., 2011; Subbaraman \& Kerr, 2015), but has been little studied. In this study, we examine predictors and consequences of this behavior in a population-based sample of high school students. Method: Self-reports were obtained from students in Quebec (Canada. The second confounder in the correlation between the frequency of cigarette smoking and canabis abuse was a family exposed to alcohol and drugs. This is in accordance with the Common Liability (CL) theory which states that the use of prohibited or non-prohibited substances is influenced by genetics and individual vulnerability. Including individual vulnerability is the vulnerability of a person to commit deviant behavior and family history of substance dependence (Prince van Leeuwen et al., 2011). Meanwhile, various studies show that a history of parents who experience substance abuse (including drugs and alcohol) is an important risk factor for experiencing drug abuse for someone (Korhornen et al., 2008; Scherrer et al., 2012).

The third Confounder was ever separated from parents for at least six months. Conceptually, students who live separately from their parents will increase their risk of committing deviant behavior due to weak supervision and communication with parents. This weak parental supervision is an important factor in drug abuse and other deviant behavior. The study found that children who do not live with their parents, their mothers or fathers will increase their risk of experiencing emotional distress, doing deviant behavior, and drug abuse, including cannabis although the impact of these conditions does not always occur (Hemovich \& Crano, 2009). The last confounder was peer influence. Having peers who use drugs and/or alcohol will surely increase the chances of being offered drugs and/or alcohol. Research showed that friends who experience substance abuse (drugs, smoking, and drinking alcohol) are also risk factors for adolescents to experience drug abuse (Korhornen et al., 2008; Scherrer et al., 2012).

The results of this multivariate analysis revealed that the correlation between the frequency of cigarette smoking and cannabis abuse of student cigarette smokers in Indonesia in 2011 might actually be influenced by other conditions owned by cigarette smokers such as history of drinking alcohol, families exposed to alcohol and or drugs, have lived separately from parents for a minimum of six months, and have peer influence. However, through multivariate analysis that has been done, the four factors have been controlled. This means in the correlation between the frequency of smoking and cannabis abuse, the four confounding variables have been identified by analyzing the differences in the distribution of risk factors/ confounding between the group of cannabis abusers and non-cannabis abusers.

\section{Conclusion}

This study concluded that the more cigarettes consumed the more survival rate of abusing cannabis increased. The more cigarettes consumed, the higher the hazard of abusing cannabis compared to cigarette smokers who rarely smoke.

\section{References}

Agrawal, A., Madden, P.A.F., Martin, N.G., \& Lynskey, M.T., 2013. Do Early Experiences with Cannabis Vary ini Cigarettes Smokers?. Drug and Alcohol Dependence, 128 (3), pp.255-259.

Astuti, N.H., 2016. Smoking is the Entrance to Cannabis Type Drug Abuse. Arkesmas, 1(1).

National Narcotics Agency of the Republic of Indonesia, \& Center for Health Research, University of Indonesia., 2017. Executive Summary of Survey Results of the National Narcotics Agency in 2016.

Badiani, A., Boden, J.M., De Pirro, S., Fergusson, D.M., Horwood, L.J., \& Harold, G.T., 2015. Tobacco Smoking and Cannabis Use in a Longitudinal Birth Cohort: Evidence of Reciprocal Causal Relationships. Drug and Alcohol Dependence, 150, pp.69-76.

Brière, F.N., Fallu, J.S., Descheneaux, A., \& Janosz, M., 2011. Predictors and Consequences of Simultaneous Alcohol and Cannabis Use in Adolescents. Addictive Behaviors, 36(7), pp.785-788.

Diaz-Guzman, E., \& Mannino, D.M., 2014. 
Epidemiology and Prevalence of Chronic Obstructive Pulmonary Disease. Clinics in Chest Medicine, 35(1), pp.7-16.

Gates, P., Jaffe, A., \& Copeland, J., 2014. Cannabis Smoking and Respiratory Health: Consideration of the Literature. Respirology, 19(5), pp.655-662.

Hemovich, V., \& Crano, W.D., 2009. Family Structure and Adolescent Drug Use: An Exploration of Single-parent Families. Substance Use and Misuse, 44(14), pp.2099-2113.

Hindocha, C., Shaban, N.D.C., Freeman, T.P., Das, R.K., Gale, G., Schafer, G., Falconer, C.J., Morgan, C.J.A., \& Curran, H.V., 2015. Associations between Cigarette Smoking and Cannabis Dependence: A Longitudinal Study of Young Cannabis Users in the United Kingdom. Drug and Alcohol Dependence, 148, pp.165-171.

Indraswari, P.I.I., Lorensia, A., \& Suryadinata, R.V., 2018. Analysis Effect of Nutrition Intake on Lung Function of Active Smoker and Non Smoker. Journal of Public Health, 14(2), pp.247-253.

Ministry of Health of the Republic of Indonesia., 2018. Hasil Utama Riskesdas 2018.

Korhonen, T., Huizink, A.C., Dick, D.M., Pulkkinen, L., Rose, R.J., \& Kaprio, J., 2008. Role of Individual, Peer, and Family Factors in the Use of Cannabis and Other Illicit Drugs: A Longitudinal Analysis Among Finnish Adolescent Twins. Drug and Alcohol Dependence, 97 (1-2), pp.33-43.

Kristman-Valente, A.N., Hill, K.G., Epstein, M., Kosterman, R., Bailey, J.A., Steeger, C.M., Jones, T.M., Abbott, R.D., Johnson, R.M., Walker, D., \& Hawkins, J.D., 2017. The Relationship Between Marijuana and Conventional Cigarette Smoking Behavior from Early Adolescence to Adulthood. Prevention Science, 428-438.

Mayet, A., Legleye, S., Chau, N., \& Falissard, B., 2011. Transition Between Tobacco and Cannabis Use Among Adolescent : A MultiStage Modelling or Progression from Onset to Daily Use. Addictive Behaviors, 36 (11), pp.1101-1105.

Nurjanah., Kresnowati, L., \& Mufid, A., 2014. Lung Function Disorders and Cotinine Levels in The Urine of Employees Who are Exposed to Secondhand Smoke. Journal of Public Health, 10(5), pp.43-52.

Öberg, M., Jaakkola, M.S., Woodward, A., Peruga, A., \& Prüss-Ustün, A., 2011. Worldwide Burden of Disease from Exposure to Secondhand Smoke: A Retrospective Analysis of Data from 192 Countries. The Lancet, 377(9760), pp.139-146.

Scherrer, J.F., Xian, H., Pan, H., Pergadia, M.L., Madden, P.A.F., Grant, J.D., Sartor, C.E., Haber, J.R., Jacob, T., \& Bucholz, K.K., 2012. Parent, Sibling and Peer Influences on Smoking Initiation, Regular Smoking and Nicotine Dependence. Results from A Genetically Informative Design. Addictive Behaviors, 37(3), pp.240-247.

Secades-Villa, R., Garcia-Rodríguez, O., Jin, C.J., Wang, S., \& Blanco, C., 2015. Probability and Predictors of the Cannabis Gateway Effect: A National Study. International Journal of Drug Policy, 26(2), pp.135-142.

Subbaraman, M.S., \& Kerr, W.C., 2015. Simultaneous Versus Concurrent Use of Alcohol and Cannabis in the National Alcohol Survey. Alcoholism: Clinical and Experimental Research, 39(5), pp.872-879.

Van Leeuwen, A.P., Verhulst, F.C., Reijneveld, S.A., Vollebergh, W.A.M., Ormel, J., Huizink, A.C., 2011. Can The Gateway Hypothesism The Common Liability Model Anad/ Or, The Route of Administration Model Predict Initiation of Cannabis Use During Adolescence? A Survival Analysis-The TRAILS Study. Journal of Adolescent Health, 48(1), pp.73-78.

Weinberger, A.H., Pacek, L.R., Wall, M.M., Zvolensky, M.J., Copeland, J., Galea, S., Nahvi, S., Moeller, S.J., Hasin, D.S., \& Goodwin, R.D., 2018. Trends in Cannabis Use Disorder by Cigarette Smoking Status in the United. Drug and Alcohol Dependence, 191(July), pp.45-51. 